Forum $2019 \cdot 34: 222$

https://doi.org/10.1007/s12312-019-0588-3

Online publiziert: 26. Februar 2019

(c) Springer Medizin Verlag GmbH, ein Teil von

Springer Nature 2019

\title{
Mit Mutmacher-Märchen dem Krebs die Stirn bieten
}

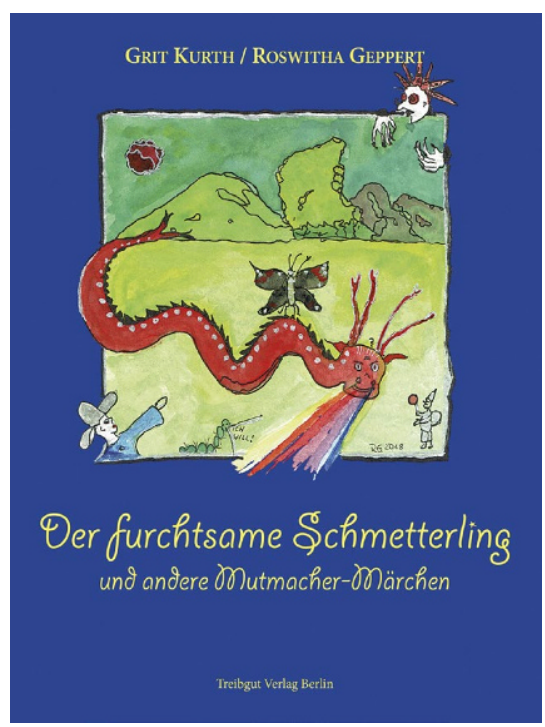

\ Das Buch „Der furchtsame Schmetterling“ von Grit Kurth und Roswitha Geppert ist erschienen im Treibgut-Verlag, 18,- Euro er oder Plakate. Auf Wunsch unterstützt der Verein auch persönlich bei der Programmgestaltung und vermittelt die $\mathrm{Au}$ toren oder Schauspieler.

Interessiert? Mehr Informationen finden Sie direkt unter https://das-leben-lesen.de/

\section{Korrespondenzadresse}

\section{Kristina Wolff}

Janssen-Cilag GmbH

Johnson \& Johnson Platz 1, 41470 Neuss,

Deutschland

kwolff@its.jnj.com

www.janssen.com/germany
Infobox Über das Haus Leben e.V.

Das Haus Leben wurde 2006 zunächst als Einrichtung des Klinikums St. Georg $\mathrm{gGmbH}$ zur psychosozialen Betreuung von Krebspatienten gegründet. Die Initiative ging von der Chefärztin der onkologischen Station aus, Dr. Luisa Mantovani Löffler, die heute als ehrenamtliche Vorstandsvorsitzende den Verein leitet. Haus Leben hat eine Vielzahl von Angeboten entwickelt, um Menschen mit Krebs bei der Bewältigung ihrer Krankheit zu unterstützen. chen handeln von Ängsten und ihrer Verarbeitung, von Liebe und Hoffnung, von Träumen und Nicht-Aufgeben. In dem phantasievollen Buch illustriert mit 19 märchenhaften Aquarellen tummeln sich Ameisen im rosa Tutu, fliegende Raupen, sprechende Glitzerschneeflocken und natürlich ein Schmetterling.

Die Rückmeldungen von Patienten und Therapeuten nach den Lesungen sind durchweg positiv: „Die Lesung war etwas ganz Besonderes.“, „Emotional sehr bewegend!“, „Die Märchen geben mir selbst Kraft, den Alltag mit den Patienten zu meistern“, um nur einige Stimmen wie- 